\title{
An Alarm Pheromone May Be Released by Defeated Competitors: A Possible Indicator of Danger
}

\author{
Ana G. Gutiérrez-García ${ }^{1,2}$, Carlos M. Contreras ${ }^{2,3, ~ *, ~ R e m e d i o s ~ M e n d o z a-L o ́ p e z ~}{ }^{4}$, \\ José Madrigal-Madariaga ${ }^{2}$ \\ ${ }^{1}$ School of Psychology, University of Veracruz, Veracruz, Mexico \\ ${ }^{2}$ Neuropharmacology section, Institute of Neuroethology, University of Veracruz, Veracruz, Mexico \\ ${ }^{3}$ Peripherical Unit, Biomedical Research Institute, National Autonomous University of Mexico, Veracruz, Mexico \\ ${ }^{4}$ Analytic Resolution Services (SARA), University of Veracruz, Veracruz, Mexico
}

\section{Email address:}

angutierrez@uv.mx (A. G. Gutiérrez-García), ccontreras@uv.mx (C. M. Contreras), remendoza@uv.mx (R. López-Mendoza), nutridep@hotmail.com (J. Madrigal-Madariaga)

\section{To cite this article:}

Ana G. Gutiérrez-García, Carlos M. Contreras, Remedios Mendoza-López, José Madrigal-Madariaga. An Alarm Pheromone May Be Released by Defeated Competitors: A Possible Indicator of Danger. American Journal of Psychiatry and Neuroscience. Vol. 3, No. 4, 2015 , pp. 70-76. doi: 10.11648/j.ajpn.20150304.13

\begin{abstract}
Among many species, the establishment of hierarchical relations contains a highly ritualized behavioral context accompanied by the delivery of volatile agents, namely ketones and aldehydes, into environment. These substances act as signals contributing to defining and maintaining social hierarchies. Among mammals, some volatile compounds are released into the environment to report the presence of danger or conflict to conspecifics. For example, rats release an alarm pheromone, 2-heptanone, through their urine when subjected to physical stress. However, it is unknown whether some similarity occurs in human being, in spite that many possible alarm compounds have been identified in human fluids, including 2-heptanone. Contact sports may represent a situation of psychosocial interaction in which some hierarchy is established at the end of the contest. In such a case, the first match in martial arts competitions represents a natural model that is seemingly useful for studying alarm conditions in humans since there are two outcomes, winner and non-winner and after a stressful situation represented by contest, some kind of hierarchy is established. The present study measured urinary concentrations of 2-heptanone using gas chromatography-mass spectrometry and applied anxiety measures (State-Trait Anxiety Inventory, STAI) in a sample of healthy student athletes. Compared with martial-arts winners, the characteristics of the non-winners included an increase in their urinary 2-heptanone content $\left(\mathrm{F}_{2,18}=5.541, \mathrm{p}<0.01\right)$, with no changes in anxiety scores (STAI-T: $\mathrm{F}_{2,18}=0.052, \mathrm{p}=0.949$; and STAI-S: $\left.\mathrm{F}_{2,18}=1.083, \mathrm{p}=0.360\right)$. The production of this ketone seems to be related with metabolic routes of fatty acids involving the participation of the so called stress hormones that may lead to an increase in the lipolysis of fatty acids and production of their metabolites, and among them, 2-heptanone. The increased release of 2-heptanone at the end of the match in non-winners may be interpreted as the release of an alarm signal that indicates imminent danger, similar to the occurrence in other species.
\end{abstract}

Keywords: Anxiety, 2-heptanone, Martial Arts, Winners, Tournament, Urine

\section{Introduction}

In animals that live in groups, confrontations are part of everyday life and occur within a highly ritualized behavioral context $[1,2]$, leading to the establishment of hierarchical relations but producing a considerable degree of stress, namely in defeated individuals [3]. Some volatile odoriferous substances are released by rodents in corporal fluids and act as signals that contribute to the establishment and maintenance of social hierarchies $[4,5]$. The preputial gland of dominant male rodents releases two ketones [6], one of which, 2-heptanone, is able to produce anxiety in another receptor conspecific [7].

In primates, some chemical signals are also released in urine during confrontations between males that compete for dominance in the hierarchy or between females that compete for food resources [8]. However, few studies have investigated the role of chemical signals in humans. Contact sports represent a ritualized conflict situation between contenders who are subjected to considerable stress $[9,10]$. Martial arts competitions may serve as a natural model of 
social interaction, in which a highly ritualized conflict situation occurs. After physical contact, in most cases, only one winner is possible, thus establishing a type of hierarchy.

Unknown are whether odoriferous substances, identified as alarm pheromones [11], are released by competitors of contact sports and whether urinary excretion is related to the result of the contest. We hypothesized that during martial arts competitions, healthy humans release chemical danger or warning signals. We compared the delivery of urinary 2-heptanone between winners and non-winners in combat sports and associated the results with measurements of anxiety a few minutes prior to the first combat in the tournament, again, a few minutes after the competitors knew the results of the first combat, and 1 week after the tournament.

\section{Materials and Methods}

The present study complied with the provisions of international codes of ethics, the Nuremberg Code, the Declaration of Helsinki of the World Medical Association, and the International Principles of Biomedical Ethics Research Council for International Organizations of Medical Sciences. Authorization was obtained from the Biomedical Research Institute Ethical Committee, Universidad Nacional Autónoma de México. Informed consent was obtained from the participants, who received information about the aims and benefits of the study. The techniques and maneuvers associated with the study did not represent any harm to the volunteers, since students only were asked to collect their urine and answer a structured anxiety inventory, three times.

\subsection{Participants}

A total sample of 20 healthy male university undergraduate student athletes, aged 18-25 years from the Universidad Veracruzana, who were selected as contenders in martial arts tournaments were invited to participate in the study. The criteria for inclusion in the study were high degrees of competitiveness (black belts), weighing 56-70 kg (depending on their category of competition), and at least six previous tournaments of experience in their respective specialties (karate do, $\mathrm{n}=6$; judo, $\mathrm{n}=14$ ). Fifteen days before the tournament, they received an explanation about how to collect their urine samples. They also received a brief explanation about the questionnaire used in the study, the State-Trait Anxiety Inventory: STAI-S (state anxiety) and STAI-T (trait anxiety) [12].

\subsection{Procedure}

The present study included three measurements of the dependent variables. The first measurement was obtained before the first match of the tournament (M1). The second was obtained $20 \mathrm{~min}$ after the competition (M2). The third was obtained 1 week after the tournament (M3). In each measurement, a urine sample was obtained, and the STAI was applied. The two measurements obtained on the day of the competition were performed in the corresponding dojo between 9:00 AM and 7:00 PM. The third measurement was obtained in the home of the competitors.

\subsection{Collection of Urine Samples and Head-Space Using Gas Chromatography-Mass Spectrometry (GC/MS) Analysis}

Urine samples $(10 \mathrm{ml})$ were collected in sterile plastic vials (Nipro Medical of México) and then immediately frozen at $-20^{\circ} \mathrm{C}$. The urine was deposited in head-space vials that were hermetically sealed with cap PTFE/silicone. The urine samples were stored at $-20^{\circ} \mathrm{C}$ and then thawed at room temperature before the analyses. The analysis of volatile compounds was performed using a gas chromatograph (Agilent Technologies, 6890N) equipped with a static head-space sampler (Agilent Technologies, 7694E). A $10 \mathrm{ml}$ urine sample was introduced into a $20 \mathrm{ml}$ head-space vial and sealed with a PTFE/silicone rubber Teflon cap. Each vial was equilibrated at $85^{\circ} \mathrm{C}$ for $45 \mathrm{~min}$ in the static head-space sampler. The head-space samples were injected into a DB-5 capillary column (J\&W Scientific, $60.0 \mathrm{~m}$ x $0.25 \mathrm{~mm} \times 0.25$ $\mu \mathrm{m}$ film thickness). The injector temperature was $250^{\circ} \mathrm{C}$, with helium $(1.0 \mathrm{ml} / \mathrm{min})$ as the carrier gas. The oven temperature was maintained at $40^{\circ} \mathrm{C}$ for $5 \mathrm{~min}$ and then increased to $210^{\circ} \mathrm{C}$ at a rate of $30^{\circ} \mathrm{C} / \mathrm{min}$. Finally, the temperature was increased to $213^{\circ} \mathrm{C}$ at a rate of $3^{\circ} \mathrm{C} / \mathrm{min}$ for $3 \mathrm{~min}$. 2-heptanone was identified by mass spectrometry using a mass detector (Agilent Technologies, 5975 inert XL). Mass spectra were obtained by ionization with electronic impact at $70 \mathrm{eV}$, and 2-heptanone was identified based on its retention indices and by matching its $70 \mathrm{eV}$ mass spectra with those contained in the mass spectra (HP Chemstation-NIST 05 Mass Spectral search program, version 2.0d) and further verified by comparison with a 2-heptanone standard (catalog no. 537683, Sigma-Aldrich) analyzed under the same conditions.

\subsection{Application and Scoring of the State-Trait Anxiety Inventory}

The STAI is a self-administered instrument. Full instructions are printed on both scales' protocols. The examine completes the instrument by filling a circle located at the right of each item. The instrument consists of two scales, one designed to measure state anxiety (STAI-S) and the other designed to measure trait anxiety (STAI-T). Each scale contains 20 items in a Likert scale with four options, ranging from "not at all" to "very much." The STAI-S and STAI-T are scored using a template according to the score weights shown on the key for each response category, and appropriate normative data are used for each scale and summed.

\subsection{Statistical Analysis}

The data were analyzed by two-way repeated-measures analysis of variance (ANOVA), with two factors: 2-heptanone measurement time-point (M1, M2, and M3) and match outcome (winner and non-winner). When the data did not fit a normal distribution, the data were ranked. The Holm-Sidak test was applied as a post hoc test when $\mathrm{p} \leq 0.05$. The results are expressed as mean \pm standard error. 


\section{Results}

\subsection{2-heptanone}

The average of the three measurements showed that the concentration of urinary 2-heptanone was consistently higher in non-winners $(6.3 \pm 1.23 \mathrm{ng} / \mathrm{ml})$ than in winners $(4.4 \pm 0.79$ $\mathrm{ng} / \mathrm{ml})$, but this difference did not reach statistical significance $\left(F_{1,18}=0.824, p=0.388\right)$. In the analysis of the measurements independent of the results of the contest, significant differences were detected $\left(\mathrm{F}_{2,18}=8.438, \mathrm{p}<0.003\right)$. Before the contest (M1), the mean urinary 2-heptanone was $5.5 \pm 1.13$ $\mathrm{ng} / \mathrm{ml}$. This concentration significantly increased $(\mathrm{p}<0.05$, Holm-Sidak test) to $7.0 \pm 1.54 \mathrm{ng} / \mathrm{ml}$ after the match (M2) and decreased below basal values 1 week later (M3: $3.5 \pm 1.03$ $\mathrm{ng} / \mathrm{ml})$.

The 2-heptanone measurement time-point $\mathrm{x}$ match outcome interaction was significant $\left(\mathrm{F}_{2,18}=5.541, \mathrm{p}<0.01\right)$. The winners maintained relatively low urinary levels of 2-heptanone throughout the three measurements, whereas urinary 2-heptanone peaked immediately after the match in the non-winners and returned to basal levels 1 week after the tournament (Figure 1).

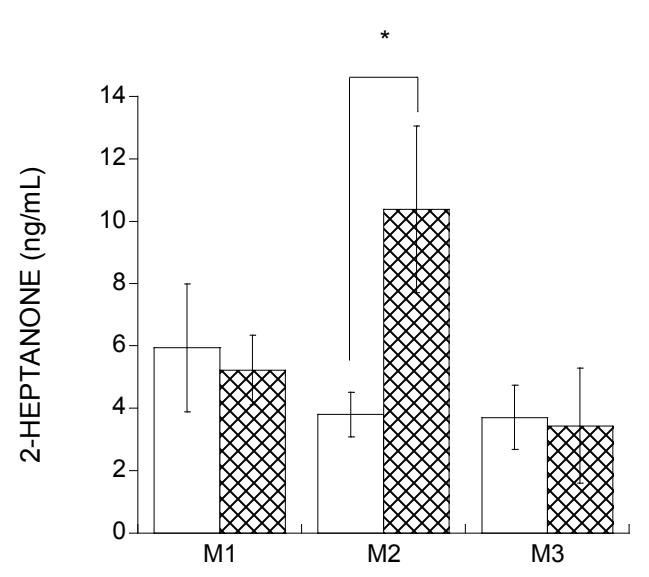

Figure 1. Urinary 2-heptanone increased at M2 (after the match) only in non-winners (hatched bars). This increase was also significant in the intragroup analysis. No significant differences were found between groups at the other measurement time-points. ${ }^{*} p<0.05$ (Holm-Sidak post hoc test).

\subsection{STAI-T}

Some differences were observed between winners $(36.4 \pm$ $1.33)$ and non-winners $(41.3 \pm 2.27)$, independent of the measurement time-points, but this difference did not reach statistical significance $\left(\mathrm{F}_{1,18}=1.228, \mathrm{p}=0.296\right)$. Significant differences were observed among measurements $\left(\mathrm{F}_{2,18}=\right.$ $3.678, \mathrm{p}<0.04)$. In both groups, the STAI-T scores slightly increased from M1 $(37.7 \pm 2.23)$ to $\mathrm{M} 2(41.0 \pm 2.61 ; \mathrm{p}<0.05$, Holm-Sidak test) and returned to basal levels by M3, 1 week after the tournament $(38.0 \pm 2.15)$. The 2-heptanone measurement time-point $\mathrm{x}$ match outcome interaction did not reach statistical significance $\left(\mathrm{F}_{2,18}=0.052, \mathrm{P}=0.949\right.$; Figure 2).

\subsection{STAI-S}

The overall analysis of the match outcome factor, independent of the measurement time-points, revealed a difference between winners $(40.3 \pm 1.63)$ and non-winners $(43.9 \pm 2.27)$, but this difference did not reach statistical significance $\left(\mathrm{F}_{1,18}=1.447, \mathrm{p}=0.260\right)$. Significant differences were observed among measurements $\left(\mathrm{F}_{2,18}=6.934, \mathrm{p}<\right.$ 0.006). Independent of the results of the competition, the scores slightly increased from M1 $(43.6 \pm 2.00)$ to M2 (45.7 $\pm 2.29 ; \mathrm{p}<0.05$, Holm-Sidak test) and decreased at M3, 1 week after the tournament $(36.9 \pm 2.64)$. The 2-heptanone measurement time-point $\mathrm{x}$ match outcome interaction did not reach statistical significance $\left(\mathrm{F}_{2,18}=1.083, \mathrm{p}=0.360\right.$; Figure 2).
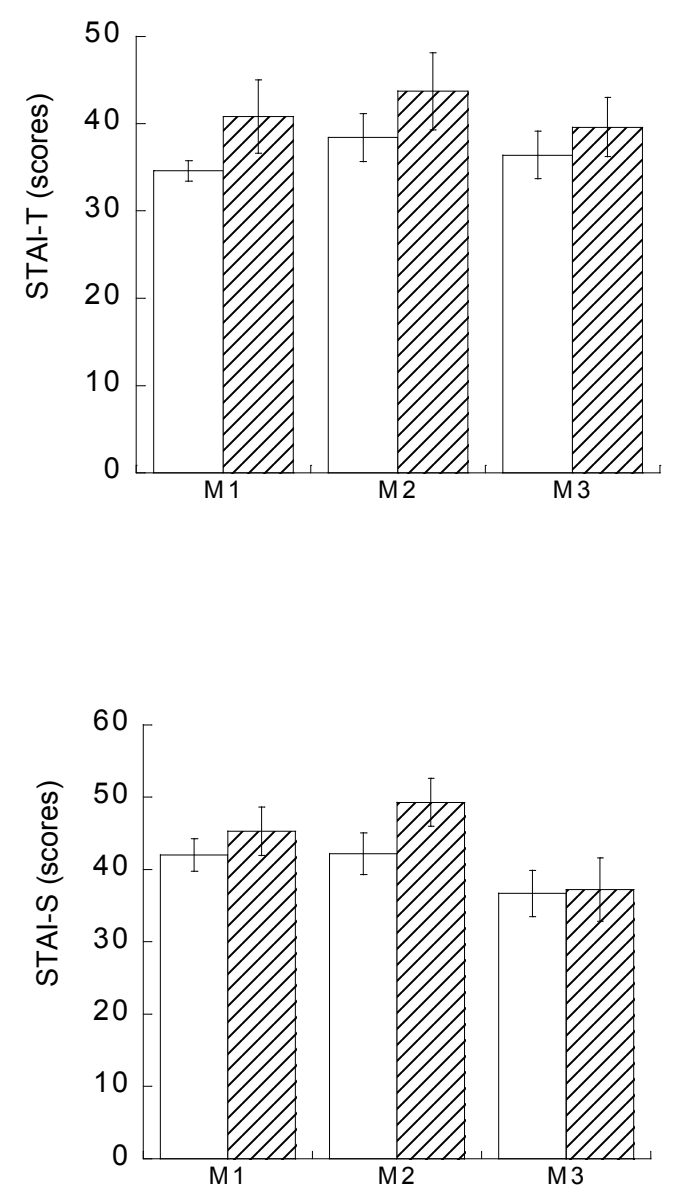

Figure 2. STAI scores. No significant differences were found between or within groups for the STAI-T subscale (upper graph) or STAI-S subscale (lower graph). Winners: empty bars; non-winners: hatched bars. Differences were revealed only when the data were pooled from both experimental groups in the global analysis by measurements (see text).

\section{Discussion}

The present study used martial arts tournaments as a possible model of a ritualized contest that consists of physical 
effort and represents a stressful situation, establishing a type of hierarchical order at the end of the competition. The results indicated that peak urinary 2-heptanone occurred only in non-winners immediately after the competition, with no relation to STAI scores.

Competition involves social stress that causes significant physiological and psychological responses that are related to strategies to cope with the situation [9, 13]. From an evolutionary point of view, competitive behavior is clearly important because it allows the maintenance of or reaching a higher category in the group, thus exerting particular effects on the social organization of the group [14]. Agonistic behavior is an adaptive behavior that is useful for achieving goals and depends only on two conditions, winning and not winning [15]. The levels of aggression differ from one sport to another [16] and depend on the context of the confrontation [17], the experience gained, the efficiency of training [18], and individual characteristics that enable competitors to undergo a process of functional adaptation [19].

In well-trained athletes, the use of images of competition and techniques directed toward improving self-confidence and relaxation are related to the intensity and duration of anxiety assessed during the competition [20]. The competitor also knows the degree of difficulty competing with different opponents, causing alertness and increased anxiety. In both groups of competitors, anxiety increased before the competition and immediately after they learned the result of the contest, and the STAI scores returned to basal levels 1 week after the tournament. Therefore, some level of anxiety was present in both groups but rapidly disappeared, and these fluctuations in anxiety scores were not related to changes in urinary 2-heptanone.

In rodents, urinary 2-heptanone increases after inescapable aversive stimulation. These levels decrease after diazepam treatment, suggesting that 2-heptanone may be a marker of anxiety but it is also able to produce anxiety in a receptor subject that detects this ketone [7, 21]. These behavioral changes modify the neuronal activity of brain structures that are responsible for processing emotional memory [22-24]. Consequently, this ketone is considered an alarm pheromone $[11,21,25]$ (i.e., a group of substances that, when released into the environment, informs other group members about the presence of danger) $[1,25]$. These substances are perceived by the vomeronasal organ, for which at least five receptor subtypes have been identified [26], whereas the human body from various sources [27] secretes 2-heptanone. Because the changes in urinary 2-heptanone observed in the present study were unrelated to changes in STAI scores, the meaning of the peak urinary content exclusively in non-winners appears to be related to fear.

Some compounds (e.g., 1-hexanol, 2-heptanone, 4-methyl-3-heptanone, and propanoic acid) are known to act as alarm pheromones in insects [28, 29]. The action of pheromones across different species and even different classes (such as insects and mammals) has been documented [30, 31]. We previously showed that 2-heptanone in the urine of stressed rats caused a state of anxiety in control rats [7].
Another study showed that 2-heptanone in the urine and milk of female mice was associated with increased aggressiveness in male mice directed toward other mice [32]. Some chemical compounds are potential alarm pheromones in the rat, including saturated aliphatic hydrocarbons (1,1-dimethoxyethane, 3-methyloctane), alcohols (2-butoxyethanol, 1-hexanol), ketones (3-hydroxy-2-butanone, 2-heptanone, 4-methyl-3-heptanone), propanoic acid, ethyl acetate, and heterocyclic 2-furaldehyde[25]. Behavioral studies that evaluated 2-heptanone as an alarm pheromone are scarce, but the use of predator odors (e.g., 2,3,5-trimethyl-3-tiazoline) produces comparable results. A single exposure to this alarm pheromone contained in fox feces and cats increased Fos expression in the lateral septal nucleus and central nucleus of the amygdala [33, 34], among other fear related structures.

In rodents in conflict situations, including fights, each of the subjects perceives anxiety differently. Some subjects react with anticipatory anxiety, freezing, and other behaviors associated with a decrease in competitive behavior [35]. In the present study, urinary 2-heptanone in non-winners peaked immediately after the competition. This ketone is released by rodents in a stressful situation $[6,11]$, in unavoidable aversive situations [7, 21], during some hormonal changes [36], in response to dominant males [6], and in other situations in which the common denominator may be the presence of danger. Notably, peak urinary 2-heptanone occurred when the non-winning competitor was informed of the result of the contest. Therefore, the meaning for this change may be the same as in other species (i.e., the announcement of danger).

2-Heptanone has largely been known as an alarm or attack pheromone found in the mandibular gland of bees and ants [37]. It is produced by several microorganisms, namely fungi [38-40], and is metabolically formed from octanoic acid [41, 42]. This $8-\mathrm{C}$ fatty acid, following a $\beta$-oxidation process, produces $\beta$-ketoacids. Once decarboxylated (i.e., losing one carbon), $\beta$-ketoacids lead to the formation of alkan-2-one compounds [43]. A 7-C ketone (i.e., a group to which 2-heptanone belongs) may be formed from an 8-C fatty acid.

Both octanoic acid and 2-heptanone, among other compounds, are naturally contained in commercial virgin coconut oil [44], goat milk [45], and caprine milk [46], among many other nutritional sources. Octanoic acid is the major component of medium-chain triglycerides, and it is susceptible to metabolic transformation in the human body [47]. Its absorption in the gastrointestinal tract is more efficient compared with long-chain fatty acids, and the transport of medium-chain fatty acids into mitochondria for oxidation occurs independently of the carnitine transport system [48]. Palmitate and octanoate oxidation was reported to be higher in muscle homogenate samples from exercise-trained volunteers compared with sedentary volunteers, with low participation from carnitine-mediated transport [49]. Therefore, the organism from fatty acids as a first step in lipolysis may synthesize 2-heptanone.

Cortisol at physiological concentrations is a potent stimulus of lipolysis in human adipose tissue [50]. The release of 
cortisol is very sensitive to stress. For example, cortisol increases in social threat or self-focus conditions in men but not in women [51]. In a rigged computer task, self-assurance was related to lower cortisol levels [52]. Such changes in cortisol plasma have also been studied in athletes.

Plasma carnitine levels decrease and acylcarnitines (the esterified form of carnitine), adrenaline, and noradrenaline levels increase at the end of a soccer game [53]. In basketball players, the levels of triglycerides, free fatty acids, and serum cortisol increase at the end of the first half of the game and remain at high levels during the second half [54]. Before and during a tennis tournament, both serum cortisol and testosterone concentrations increased [55]. In male judo competitors, cortisol levels and anxiety scores increased even before the contest, and a higher increase relative to resting conditions was related to a better match outcome [56]. Interestingly, in badminton [57] and hockey [58] players, defeat is related to an increase in cortisol levels, whereas winners exhibit an increase in testosterone. Therefore, stress situations lead to increased levels of cortisol. In non-winners, a higher level of cortisol seemingly occurs, which may lead to an increase in the lipolysis of fatty acids and production of their metabolites. This possibility remains to be explored.

\section{Conclusion}

In the present study, we found that the human concentrations of urinary 2-heptanone peaked only in non-winners after the competition, which may represent a chemical signal that prevents danger by announcing some dangerous situation to conspecifics. In this case, 2-heptanone may be conceived as a pheromone indicating fear rather than anxiety, taking into account, that its delivery may be influenced by other factors, such as the presence or not of some audience, personality traits and resilience to stress, among others aspects.

\section{Acknowledgements}

The authors thank Michael Arends for revising and editing the English of the manuscript. Cuerpo Académico UVE-CA-25 and Programa de Fortalecimiento Académico del Posgrado de Alta Calidad I010/458/2013, C-703/2013).

\section{References}

[1] D.C. Blanchard, R.J. "The colony model of aggression and defense". In: D.A Dewsbury. Contemporary issues in comparative psychology. Sunderland, Massachusetts: Sinauer Associates, pp. 124-137, 1990.

[2] D.C. Blanchard, R.R. Sakai, B. McEwen, S.M. Weiss, R.J. Blanchard. "Subordination stress: behavioral, brain, and neuroendocrine correlates". Behav Brain Res, 58:113-121, 1993.

[3] R.J. Blanchard, D.C. Blanchard, K.J. "Social stress, mortality and aggression in colonies and burrowing habitats". Behav Proces, 11:209-213, 1985.
[4] B. Jemiolo, T.M. Xie, M. Novotny. "Urine marking in male mice: responses to natural and synthetic chemosignals". Physiol Behav, 52:521-526, 1992.

[5] M. Novotny, S. Harvey, B. Jemiolo. "Chemistry of male dominance in the house mouse, Mus domesticus". Experientia, 15:109-113, 1990.

[6] L.A. Pohorecky, G.G. Blakley, H.A. Soini, D. Wiesler, K.E. Bruce, M.V. Novotny. "Social housing influences the composition of volatile compounds in the preputial glands of male rats". Horm Behav, 53:536-545, 2008.

[7] A.G. Gutiérrez-García, C.M. Contreras, R. Mendoza-López, S. Cruz-Sánchez, O. García-Barradas, J.F. Rodríguez-Landa, B. Bernal-Morales. "A single session of emotional stress produces anxiety in Wistar rats”. Behav Brain Res, 167:30-35, 2006.

[8] L.J. Alport. "Comparative analysis of the role of olfaction and the neocortex in primate intrasexual competition". Anat Rec A Discov Mol Cell Evol Biol, 281:1182-1189, 2004.

[9] A. Salvador. "Coping with competitive situations in humans". Neurosci Biobehav Rev, 29:195-205, 2005.

[10] T.R. Zazryn, P.R. McCrory, P.A. Cameron. "Neurologic injuries in boxing and other combat sports". Neurol Clin, 26: 257-270, 2008.

[11] R. Hauser, M. Wiergowski, M. Kaliszan, T. Gos, G. Kernbach-Wighton, M. Studniarek, Z. Jankowski, J. Namiesnik. "Olfactory and tissue markers of fear in mammals including humans”. Med Hypotheses, 77:1062-1067, 2011.

[12] C.D. Spielberg, R. Díaz-Guerrero. "IDARE. Inventario de Ansiedad: Rasgo-Estado". México City: Manual Moderno, 1975.

[13] A. Salvador, R. Costa. "Coping with competition: neuroendocrine responses and cognitive variables". Neurosc Biobehav Rev, 33:160-170, 2009.

[14] R.J. Blanchard, C.R. McKittrick, D.C. Blanchard. "Animal models of social stress: effects on behavior and brain neurochemical systems". Physiol Behav, 73:261-271, 2001.

[15] R. Costa, A. Salvador. "Associations between success and failure in a face-to-face competition and psychobiological parameters in young women". Psychoneuroendocrinology, 37:1780-1790, 2012.

[16] E. Reynes, J. Lorant. "Competitive martial arts and aggressiveness: a 2-yr. longitudinal study among young boys". Percept Mot Skills, 98:103-115, 2004.

[17] W. Lamarre, T.A. Nosanchuk. "Judo-the gentle way: a replication of studies on martial arts and aggression". Percep Motor Skills, 88:992-996, 1999.

[18] E. Franchini, S. Sterkowicz, C.M. Meira, F.R. Gómes, G. Tani. "Technical variation in a sample of high level judo players". Percept Mot Skills, 106:859-869, 2008.

[19] E.L. Melanson. "Resting heart rate variability in men varying in habitual physical activity". Med Sci Sports Exerc, 32:1894-1901, 2000.

[20] R. Wadey, S. "Basic psychological skills usage and competitive anxiety responses: perceived underlying mechanisms". Res Q Exerc Sport, 79:363-373, 2008. 
[21] A.G. Gutiérrez-García, C.M. Contreras, M.R. Mendoza-López, O. García-Barradas, J.S. Cruz-Sánchez. "Urine from stressed rats increases immobility in receptor rats forced to swim: role of 2-heptanone". Physiol Behav, 91:166-172, 2007.

[22] C.M. Contreras, A.G. Gutiérrez-García, T. Molina-Jiménez, M.R. Mendoza-López. "2-Heptanone increases the firing rate of the basal amygdala: role of anterior olfactory epithelial organs". Neuropsychobiology, 66:167-173, 2012.

[23] C.M. Contreras, A.G. Gutiérrez-García, T. Molina-Jiménez. "Anterior olfactory organ removal produces anxiety-like behavior and increases spontaneous neuronal firing rate in basal amygdala”. Behav Brain Res, 252:101-109, 2012.

[24] T. Molina-Jiménez, A.G. Gutiérrez-García, C.M. Contreras. "An alarm pheromone increases the responsivity of amygdaline-hippocampal neurons". Salud Mental, 36(4):279-284, 2013.

[25] R. Hauser, M. Wiergowski, G. Kernbach-Wighton, J. Namieśnik, M. Kaliszana.” study to identify olfactory markers of fear in rats a humans". JSIMA, 3:82-84, 2011.

[26] I. Rodríguez, C.A. Greer, M.Y. Mok, P. Mombaerts. "A putative pheromone receptor gene expressed in human olfactory mucosa". Nature Genetics, 26:18-19, 2000.

[27] B. de Lacy Costello, A. Amann, H. Al-Kateb, C. Flynn, W. Filipiak, T. Khalid, D. Osborne, N.M Ratcliffe. "A review of the volatiles from the healthy human body." J Breath Res, 8(1):014001, 2014.

[28] B.R. Wager, MD. Breed. "Does honey bee sting alarm pheromone give orientation information to defensive bees?" Ann Entomol Soc Am, 93:1329-1332, 2000.

[29] W.O. Hughes, P.E. Howse, D. Goulson. "Mandibular gland chemistry of grass-cutting ants: species, caste, and colony variation". J Chem Ecol, 27:109-124, 2001.

[30] L.E. Rasmussen, T.D. Lee, W.L. Roelofs, A. Zhang, Jr.G.D.Daves. "Insect pheromone in elephants. Nature, 379:684, 1996.

[31] L.E. Rasmussen, T.D. Lee, A. Zhang, W.L. Roelofs, Jr.G.D. Daves. "Purification, identification, concentration and bioactivity of (Z)-7-dodecen-1-yl acetate: sex pheromone of the female Asian elephant (Elephas maximus)". Chem Senses, 22:417-437, 1997.

[32] Z. Wang, C. Balet-Sindreu, V. Li, A. Nudelman, G.C. Chan, D.R. Storm. "Pheromone detection in male mice depends on signaling through the type 3 adenylyl cyclase in the main olfactory epithelium". J Neurosci, 26:7375-7379, 2006.

[33] H.E. Day, C.V. Masini, S. Campeau. "The pattern of brain c-fos mRNA induced by a component of fox odor, 2,5-dihydro-2,4,5-trimethylthiazoline (TMT), in rats, suggests both systemic and processive stress characteristics". Brain Res, 1025:139-151, 2004.

[34] L.G. Staples, G.E. Hunt, J.L. Cornish, I.S. McGregor. "Neural activation during cat odor-induced conditioned fear and 'trial 2 ' fear in rats”. Neurosci Biobehav Rev, 29:1265-1277, 2005.

[35] M. Martínez, A. Calvo-Torrent, M.A. Picó-Alfonso. "Social defeat and subordination as models of social stress in laboratory rodents: a review". Aggress Behav, 24:241-256, 1998.
[36] F.J. Schwende, D. Wiesler, M. Novotny. "Volatile compounds associated with estrus in mouse urine: potential pheromones". Experientia, 40:213-215, 1984.

[37] M.J. Carroll, A.J. Duehl. "Collection of volatiles from honeybee larvae and adults enclosed on brood frames". Apidologie, 43:715-730, 2012.

[38] R.F. Gehrig, S.G. Knight. "Formation of ketones from fatty acids by spores of Penicillium roqueforti". Nature, 182:1237, 1958.

[39] P. Pasanen, A. Korpi, P. Kalliokoski, A.L. Pasanen. "Growth and volatile metabolite production of Aspergillus versicolor in house dust". Environ Int, 23:425-432, 1997.

[40] S. Cakmakci, E. Dagdemir, A.A. Hayaloglu, M. Gurses, B. Cetin, D. Tahmas-Kahyaoglu. "Effect of Penicillium roqueforti and incorporation of whey cheese on volatile profiles and sensory characteristics of mould-ripened Civil cheese". Int J Dairy Technol, 66:512-526, 2013.

[41] C. Larroche, I. Besson, J.B. Gros. "Behavior of spores of Penicillium roquefortii during fed-batch bioconversion of octanoic acid into 2-heptanone". Biotechnol Bioeng, 44:699-709, 1994.

[42] C. Larroche. "Internal substrate concentrations during biotransformation of octanoic acid into 2-heptanone by spores of Penicillium roquefortii". J Ind Microbiol Biotechnol, 16:29-35, 1996.

[43] P.H. Van der Schaft, N. Ter Burg, S. Van den Bosch, A.M. Cohen. "Fed-batch production of 2-heptanone by Fusarium poae". Appl Microbiol Biotechnol, 36:709-711, 1992.

[44] J.E.R. Santos, B.J. Villarino, A.R. Zosa, F.M. Dayrit "Analysis of volatile organic compounds in virgin coconut oil and their sensory attibutes”. Philip J Sci, 140:161-171, 2011.

[45] F.J. Delgado, J. González-Crespo, R. Cava, R. Ramírez. "Formation of the aroma of a raw goat milk cheese during maturation analysed by SPME-GC-MS". Food Chem, 129:1156-1163, 2011.

[46] A.F. Atasoy, A.A. Hayaloglu, H. Kirmaci, O. Levent, H. Türkoğlu. "Effects of partial substitution of caprine for ovine milk on the volatile compounds of fresh and mature Urfa cheeses". Small Rum Res, 115:113-123, 2013.

[47] V.P. Carnielli, E.J. Sulkers, C. Moretti, J.L. Wattimena, J.B. van Goudoever, H.J. Degenhart, F. Zacchello, P.J. Sauer. "Conversion of octanoic acid into long-chain saturated fatty acids in premature infants fed a formula containing medium-chain triglycerides". Metabolism, 43:1287-1292, 1994.

[48] A.A. Papamandjaris, D.E. MacDougall, P.J. Jones. "Medium chain fatty acid metabolism and energy expenditure: obesity treatment implications". Life Sci, 62:1203-1215, 1998.

[49] K. Jong-Yeon, R.C. Hickner, G.J. Dohm, J.A. Houmard. "Long- and medium-chain fatty acid oxidation is increased in exercise-trained human skeletal muscle". Metabolism, 51:460-464, 2002.

[50] C.B. Djurhuus, C.H. Gravholt, S. Nielsen, A. Mengel, J.S. Christiansen, O.E. Schmitz, N. Møller. "Effects of cortisol on lipolysis and regional interstitial glycerol levels in humans". Am J Physiol Endocrinol Metab, 283:E172-177, 2002. 
76 Ana G. Gutiérrez-García et al.: An Alarm Pheromone May Be Released by Defeated Competitors: A Possible Indicator of Danger

[51] T.F. Denson, J.D. Creswell, I. Granville-SmithI.”Self-focus and social evaluative threat increase salivary cortisol responses to acute stress in men”. J Behav Med, 35:624-633, 2012.

[52] S. Zilioli, N.V. Watson. "Winning isn't everything: mood and testosterone regulate the cortisol response in competition". PLoS One, 8(1):e52582, 2013.

[53] K.H. Schulpis, T. Parthimos, E.D. Papakonstantinou, T. Tsakiris, M. Parthimos, A.F. Mentis, S. Tsakiris. "Evidence for the participation of the stimulated sympathetic nervous system in the regulation of carnitine blood levels of soccer players during a game". Metabolism, 58:1080-1086, 2009.

[54] N. Ben Abdelkrim, C. Castagna, S. El Fazaa, Z. Tabka, J. El Ati. "Blood metabolites during basketball competitions". J Strength Cond Res, 23:765-773, 2009.
[55] T. Ojala, K. Häkkinen. "Effects of the tennis tournament on players' physical performance, hormonal responses, muscle damage and recovery”. J Sports Sci Med, 12:240-248, 2013.

[56] A. Salvador, F. Suay, E. González-Bono, M.A. Serrano. "Anticipatory cortisol, testosterone and psychological responses to judo competition in young men". Psychoneuroendocrinology, 28:364-375, 2003.

[57] M. Jiménez, R. Aguilar, J.R. Alvero-Cruz. "Effects of victory and defeat on testosterone and cortisol response to competition: evidence for same response patterns in men and women". Psychoneuroendocrinology, 37:1577-1581, 2012.

[58] R. Aguilar, M. Jiménez, J.R. Alvero-Cruz. "Testosterone, cortisol and anxiety in elite field hockey players". Physiol Behav, 119:38-42, 2013. 